Perceptual and Motor Skills, 1987, 64, 119-125. (C) Perceptual and Motor Skills 1987

\title{
EFFECT OF PRIME TYPE ON LEXICAL DECISION TIME ${ }^{1}$
}

\author{
SALVADOR ALGARABEL, ALFONSO PITARQUE, MARIA JOSE SOLER, \\ JUAN CARLOS RUIZ, JUAN MANUEL BAIXALILI, AND CARMEN DASI \\ University of Valencia
}

\begin{abstract}
Summary.-The present investigation concerns the issues of the control condition and type of related prime-target relationship operationalization in the lexical-decision paradigm. It is shown that the use of a row of asterisks produces strong inhibitary effects on reaction time to the target relative to a control condition formed with the word "neutro" ("neutral"). The operationalization of prime-target relatedness by means of association or category norms seems equally adequate, although category exemplars do not prime category exemplar targets. Both sets of data are discussed in relation to current research trends using lexical-decision time.
\end{abstract}

Spreading activation has become a key concept in the modelling of the functioning of memory retrieval. Activation could be described as an energy wave which originates in the concept currently being processed in memory and extends in parallel to all neighbouring concepts semantically related to it, thereby making them more readily available for processing. The amount of work devoted to the study of activation with the lexical-decision paradigm is impressive (Lupker, 1984; Fischler, 1977; Neely, 1977). In addition to this empirical work, several theoretical formulations use the concept or try to delimit its properties (Anderson, 1983; Posner \& Snyder, 1975). In spite of this intensive work, there are few points of agreement, and some of the controversies affect directly the basic methodology of the lexical-decision paradigm, the primary interest of the present paper.

In a lexical-decision paradigm, the subject sees a sequence of two stimuli, prime and targer, and has to respond to the second on the basis of its lexical status (word-nonword). The usual result is that decision time is facilitated if the prime and target are semantically related. This is interpreted as the direct result of spreading activation.

In this context, two points deserve special attention. One is the issue of the appropriate control condition in relation to which facilitation or inhibition of processing has to be assessed, and the other, is the definition of semantic relacedness.

Neely (1977) and many researchers (Becker, 1980; Kiger \& Glass, 1983) have used a row of asterisks as control condition. This control condition is supposed to produce neither facilitation nor inhibition in the processing of the

\footnotetext{
${ }^{3}$ Requests for reprints should be sent to Salvador Algarabel, Facultad de Psicología, Universidad de Valencia, Blasco Ibañez, 21, 46010 Valencia, Spain.
} 
target word. That is, a meaningless string of symbols, e.g., a row of asterisks, bears no resemblance to any word constructed according to orthographic rules and therefore does not activate any memory node but serves as baseline against which to assess the possible facilitatory or inhibitory effects of related or unrelated prime-target sequences (Posner \& Snyder, 1975).

However, several researchers have questioned the status attributed to a string of asterisks as control condition. Antos (1979), and later deGroot, Thomassen, and Hudson (1982) have attributed to this control condition inhibitory properties, that if true would lead to overestimation of the facilitating effects of the related-target condition.

Part of the problem arises from the observed difference in reaction time between word prime-pseudoword target and asterisk prime-pseudoword target conditions. The advantage for word-pseudoword target (shorter latencies) has been attributed by Antos (1979) and deGroot, et al. (1982) to inhibitory powers of asterisks, whereas Neely (1977) has suggested that word primes in a word-pseudoword condition have facilitatory effects. deGroot, et al. (1982) thoroughly investigated the problem, using the word "blanco" ("blank" in Dutch) as a control, finding that the row of asterisks produced inhibitory effects on both word and pseudoword target trials.

The second interesting issue is associated with the type of operationalization of semantic relatedness. Association and category norms are the two universal forms for operationalization of semantic relatedness. On the one hand, it seems that association norms being based precisely on instructions to answer with "the first word that comes to mind" are a direct reflection of semantic proximity. Category norms, on the other hand, are based on belongingness and are therefore a more indirect measure of semantic closeness. On the basis of this analysis association norms mighe be a better tool for the study of priming, at least better than intracategory pairings. The question of the appropriate operationalization of semantic relatedness does not seem trivial, because both procedures are used quite frequently, and their use may confound orher aspects of the experimental design.

The purpose of the experiment reported in this paper is twofold. First of all, deGroot, et al. (1982) and before her, Antos (1979) showed the problem the lexical-decision paradigm faces with the control condition. Our aim was to replicate some of the conditions presented by deGroot, et al. (1982) to compare the behavior of two different baseline conditions, one of them is the classical row of asterisks and the other the word "neutro" (neutral).

The second question investigated here concerns the type of operationalization carried out in the lexical-decision experiment to form the 'related' condition. Most researchers have used association norms (Palermo \& Jenkins, 
1964), reflecting the fact that prime and target must be associatively instead of semantically related, though both aspects are tied together most of the rime. The use of category norms (Battig \& Montague, 1969) could be a direct consequence of defining prime-target relationship as semantic rather than associative, on the one hand, and the search for proofs of the nonautomatic kind of activation according to Posner and Snyder. We investigated here the degree of facilitation in lexical-decision time according to the type of definition of prime-target relationship. This relationship could be associative (association norms), semantic general (category label prime-exemplar target) or semantic specific (exemplar prime-exemplar target).

\section{METHOD}

\section{Subjects}

Undergraduates of the University of Valencia volunteered from a second-year course in psychology. Seventeen of them were women and two men.

\section{Materials and Design}

The stimuli were words extracted from Spanish category norms (Pascual, Gotor, Miralles, \& Algarabel, 1979), and free-association norms (Algarabel, Sanmartin, Garcia, \& Espert, 1986). The selected free associates were the stimuli and their highest ranking response given in the norms. All words extracted from the association norms appeared only once throughout the experiment. Category labels were selected from those easily expressed as a single word and written in singular. All category exemplars were extracted from 13 different categories, and their frequencies were equal to or higher than 9. Given these restrictions, most category exemplars appeared once but a reduced set appeared between two and four times. Category labels were "color" (colour), "animal" (animal), "bebida" (drink), "deporte" (sport), "arbol" (tree), "condimento" (dressing), "delito" (offence), "flor" (flower), "prenda" (article of clothing), "mueble" (furniture), "metal" (metal) and were repeated berween 3 and 11 times, depending on the availability of words within caregories.

The 192 word-target trials were divided in eight groups, according to the prime-targer word relationship. Twenty-four primes were category exemplars related to the target exemplars because both belonged to the same category. Twenty-four primes were the category names of their corresponding target exemplars, and 24 were first or second associates to targets according to free-association norms. Each one of these manipulations had its nonrelated counterpart; 24 nonrelated exemplars, 24 nonrelated category names, and 24 nonrelated words extracted from the free-association norms. Two 
control conditions were used, a row of seven asterisks and the word 'neutro'. Within each prime-word group, the three prime durations (with an interstimulus interval of zero) were equally represented, yielding for analysis to eight observations per cell.

Pseudowords were constructed replacing one or two letters of a word matched in length to actual words used in the experiment. The 192 pseudoword-target trials were divided according to prime type in three categories: "neutro," "\#**\#\#," and word prime. Ninety-six trials were control trials, and the other 96 were word primes, extracted from the same pool as in the word-target conditions.

\section{Procedure}

Subjects were run individually under control of an Apple Ile microcomputer. The microcomputer randomized a different sequence of trials for each subject, and timed the response. Each trial was initiated presenting a fixation cross $(+)$ in the upper left side of the screen. The cross stayed on for $450 \mathrm{msec}$. Immediately and replacing the cross, the prime appeared for 150,450 , or $900 \mathrm{msec}$. and was replaced by the target. The subject's response terminated the target and initiated a 2 -sec. intertrial interval during which no stimuli appeared on the screen.

Subjects were asked to respond as fast as possible without loss of accuracy. The computer indicated after each trial if the response was incorrect, showing the message 'incorrect' in inverse characters.

\section{RESULTS}

The errors were $2.55 \%$ of the total responses with a very small between subjects variation ( $1.04 \%$ to $3.91 \%$ ). Given the small percentage of errors no further analysis of these data were undertaken.

Any subject's response outside the criterion of mean \pm 2 standard deviations was eliminated from the analysis. The remaining responses corresponding to word-targec trials were submitted to an 8 (type of prime) $\times 3$ (asynchrony) analysis of variance. The analysis was made considering materials and subject as random variables (Clark, 1973). $F_{1}, F_{2}$, and $m i n F^{\prime}$ are reported.

The effect of prime type was significant in both analyses $\left(F_{1(7.126)}=\right.$ 25.62, $P<.01, M S e=3673.48, F_{2(7,49)}=6.92, P<.01, M S e=15317.95$, $\left.\min F^{\prime}{ }_{7.18}=5.45, P<.01\right)$.

The effect of stimulus asynchrony was significant in both analyses $\left(F_{1(2.36)}\right.$ $=6.83$, Mse $=15317.95, p<.01, F_{2(2,168)}=6.22, p<.01$, and its $\operatorname{minF}^{\prime}$ was marginally significant, $m i n F_{2,27}^{\prime}=3.26, p>.05$ ). The interaction of prime type and stimulus asynchrony was significant in the subject analysis $\left(F_{1(14,252)}=3.30, \mathrm{MSe}=3623.93\right)$ but not in the item analysis $\left(F_{2(14,168)}<\right.$ $\left.1.00, \min ^{\prime}{ }_{14.8}<1.00\right)$. 
TABLE 1

MeAN FaCilitation (MSEC.) FOR DiffERENT Word-taRget CONDITIONS

\begin{tabular}{ccc}
\hline \hline \multirow{2}{*}{ Type of Experimental Condition } & \multicolumn{2}{c}{ Type of Control Prime } \\
\cline { 2 - 3 } & "Neutro" & 77 \\
Exemplars & 43 & 65 \\
Related & 31 & \\
Nonrelated & & 107 \\
Categories & 73 & 40 \\
Related & 6 & 127 \\
Nonrelated & & 55 \\
Associates & 93 & \\
Related & 21 & \\
Nonrelated & & \\
\hline
\end{tabular}

Newman-Keuls tests were carried out taking $M S_{\text {error }}$ from the $F_{1}$ analysis as the error term for the test. This analysis produced a quite clear partern of significant differences.

First of all, the condition in which the prime was a related associate was different from any other condition except that in which category was the prime. The related associates were not different from the nonrelated exemplars

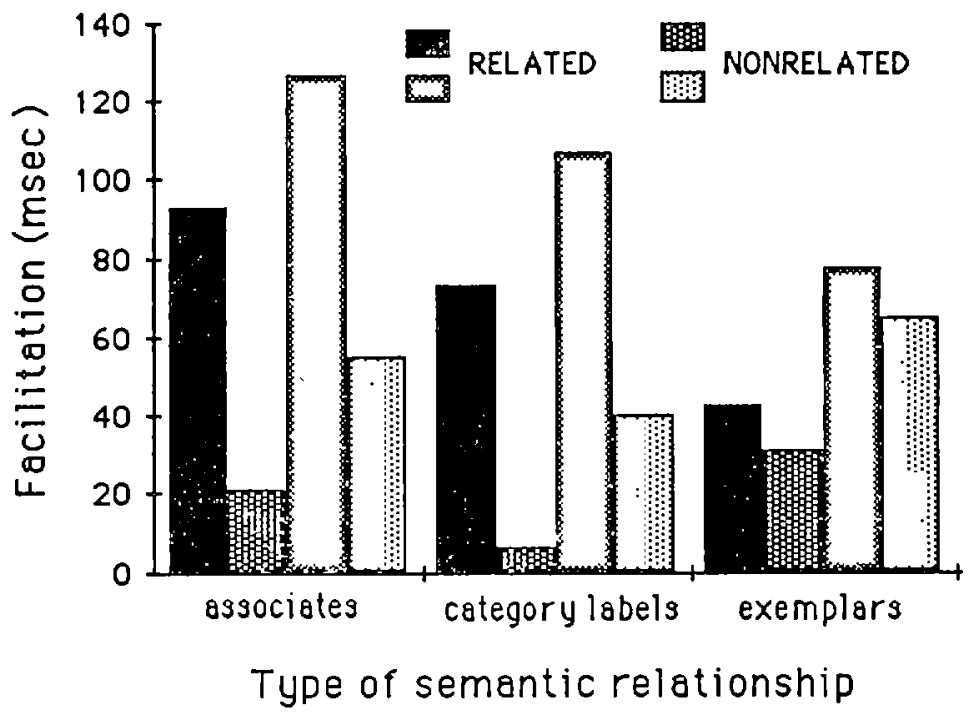

FIG. 1. Amount of facilitation (msec.) as a function of type of prime (associate, category, exemplar), prime-target relationship (related, unrelated) measured from the word "neutro" ("neutral") as a control (first two bars in each level of the independent variable) or from "witw*:ats" as prime control (second two bars in each level of the independent variable 
and the nonrelated category words. More important, all the nonrelated conditions were not significantly different from the 'neutro' condition, except the nonrelated exemplars $(p=.05)$, but all of them were significantly different from the asterisk control condition. Fig. 1 and Table 1 present the main results as facilitarion measures obtained by subtracting each reaction time from the appropriate control.

Analysis of variance carried out on pseudoword data showed no significant effect of either prime type, stimulus asynchrony, or their interaction.

\section{Discussion}

One of the first purposes of this experiment was to investigate the issue of the control condition in lexical decision. Once more, the present experiment shows the inadequacy of using a row of asterisks as the neutral condition. The data indicate that reaction time to the target in this situation is inhibited, leading to an overestimation of the facilitatory effects and underestimation of the inhibitory effects, probably caused by attentional fatigue produced by successive repetitions of the prime control. Theoretical expectations (Posner \& Snyder, 1975) would predict no difference between the control and nonrelated conditions for the 150 - and 450 -msec. stimulus-onset asynchronies, and the appearance of inhibitory effect at $900-\mathrm{msec}$. stimulus-onset asynchrony. The Newman-Keuls test showed that the "neurro" condition produced such a pattern of results, except the difference was only marginally significant. However, no trace of inhibition was found as in orher recent results (Patton \& Lefton, 1985). An important point to appreciate is that the word "neutro" must acquire its control status only after some initial repetitions because otherwise its status is the same as the unrelated words, producing inhibitory effects. This means that its first presentations should, depending on stimulus-onset asynchrony, also be inhibitory. One solution to this difficult problem would be to drop the control condition (Jonides \& Mack, 1984), but then we would be unable to assess the inhibitory or facilitatory components of lexical decision time.

In relation to the second question posed by the present experiment, the Newman-Keuls tests show that category exemplars do not reflect correctly prime-target relatedness, and in fact the related ones do not differ from nonrelared exemplars in reaction time. This is not a surprising result and probably reflects the fact that words as exemplars are too concrete to be used both as prime and targets which are situated at similar hierarchical levels and with few direct links among them. On the other hand, the experiment shows the adequacy of using association or category norms (category label-exemplars) in lexical-decision experiments alchough the mechanism(s) by means of which both are effective cannot be determined clearly from this study. 


\section{REFERENCES}

Algarabel, S., Sanmartin, J., Garcia, J., \& Espert, R. (1986) Normás de asociacion libre para investigación experimental. Informes del Departamento de Psicologia Experimental, Universidad de Valencia.

ANDERSON, J. R. (1983) A spreading activation theory of memory. Journal of Verbal Learning and Verbal Behavior, 22, 261-295.

ANTos, S. (1979) Processing facilitation in a lexical decision task. Journal of Experimental Psycbology: Human Perception and Performance, 5, 527.545.

BatTig, W. F., \& MONTAGUE, W. E. (1969) Category norms for verbal items in 56 categories. A replication and extension of the Connecticut category norms. Journal of Experimental Psychology Monograph, 80 (3, Pt. 2).

BeCKER, C. A. (1980) Semantic context effects in visual word recognition: an analysis of semantic strategies. Memory and Cognition, 8, 493-512.

CLARK, H. H. (1973) The language-as-fixed effect fallacy: a critique of language statistics in psychological research. Journal of Verbal Learning and Verbal Bebavior, 12, 335.359.

de Groot, A. M. B., Thomassen, A. J. W. M., \& Hudson, P. T. W. (1982) Associative facilitation of word recognition as measured from a neutral prime. Memory and Cognition, 10, 358-370.

FISCHLER, I. (1977) Associative facilitation without expectancy in a lexical decision task. Journal of Experimental Psycbology: Human Perception and Performance, $3,18-26$.

JONIDES, J., \& MACK, R. (1984) On the cost and benefit of cost and benefit. Psycbological Bulletin, 96, 29-44.

JUilland, A., \& Chang-Rodriguez, E. (1964) Frequency dictionary of Spanish words. London: Mouton.

KIGER, J. I., \& GLASS, A. L. (1983) The facilitation of lexical decision by a prime occurring after the target. Memory and Cognition, 11, 356-365.

LUPKER, S. J. (1984) Semantic priming without association: a second look, Journal of Verbal Learning and Verbal Bebavior, 23, 709-733.

NeEly, J. H. (1976) Semantic priming and retrieval from lexical memory: roles of inhibitionless spreading activation and limited-capacity attention. Journal of Experimenial Psychology: General, 106, 226.254.

Palermo, D. S., \& Jenkins, J. J. (1964) Word association norms: grade school tbrougb college. Minneapolis, MN: Univer. of Minnesota Press.

Pascual, J., Gotor, A., Miralles, J. L., \& Algarabel, S. (1979) Normas categoriales para el estudio de la memoria humana (Resumen). Actas del cangreso nacional de Psicologia. Pamplona: Sociedad Española de Psicología. P. 74.

PATTON, B. L., \& LEFTON, L. A. (1985) Facilitation without inhibition. Bulletin of the Psychonomic Society, 23, 191-194.

PosNer, M. I., \& SNYDer, C. R. R. (1975) Attention and cognitive control. In R. L. Solso (Ed.), Information processing and cognition: the Loyola symposium. Hillsdale, NJ: Erlbaum.

VANDERwart, M. (1984) Priming by pictures in lexical decision. Journal of Verbal Learning and Verbal Bebavior, 23, 67-83.

Accepted October 30, 1986. 
This article has been cited by:

1. Koichiro Matsuno, Jun Lu. 1989. A word of a natural language has 2.718 different meanings or slightly more. Biosystems 22, 301-304. [CrossRef] 